\title{
Entre a Filologia e a Lexicografia Histórica: notas sobre a elaboração de uma edição das cantigas satíricas do Cancioneiro da Biblioteca Nacional para o estudo do léxico Between Philology and Historical Lexicography: notes about the
elaboration of a satirical song edition from the Cancioneiro da
Biblioteca Nacional for lexicon study purposes
}

Lisana Rodrigues Trindade Sampaio*

Universidade Federal do Recôncavo da Babia, Amargosa, BA, Brasil

\begin{abstract}
Resumo: $O$ presente estudo concentra-se na apresentação do processo de elaboração de uma edição diplomática das cantigas satíricas do Cancioneiro da Biblioteca Nacional (ou Colocci-Brancuti) para composição de um vocabulário das formas verbais, finitas e infinitivas, patentes nessas cantigas, produzido a partir dos preceitos da Lexicografia Histórica, com vistas a contribuir com o trabalho de reconstrução da trajetória da língua portuguesa no período arcaico. Ressalta-se aqui a importância do acesso à documentação remanescente a partir dos acervos digitais disponibilizados por algumas bibliotecas, o que tem permitido a observação da riqueza dos dados linguísticos desses códices, a fim de preservar todos os aspectos que possam dar pistas para a investigação e registro da língua patente nesses fragmentos do tempo.
\end{abstract}

Palavras-chave: Filologia. Lexicografia Histórica. Cantigas satíricas. Cancioneiro da Biblioteca Nacional. Léxico da língua portuguesa.

\begin{abstract}
The present work focuses on presenting the elaboration process of a diplomatic edition of satirical songs - or cantigas satiricas - of the Cancioneiro da Biblioteca Nacional (Colocci-Brancuti) - also known as the Biblioteca Nacional's Songbook - with the purpose of developing a finite and infinitive verbal forms vocabulary, patented in these songs, being produced based upon the Historical Lexicography precepts, with the intention of contributing to the work of reconstructing the trajectory of the Portuguese language during the archaic period. Emphasized here is the importance of the access to the remaining documents through digital archives provided by some libraries and their platforms, which has allowed the observance of the linguistic data richness of these codices in order to preserve all aspects that could offer clues to an investigation and registration of the patented language in troubadour songs.
\end{abstract}

Keywords: Philology. Historical Lexicography. Satirical songs. Cancioneiro da Biblioteca Nacional. Lexicon of the Portuguese language.

\section{INTRODUÇÃO}

As últimas décadas se caracterizaram por um notável avanço tecnológico que passou a fomentar possibilidades de pesquisa e ensino de língua portuguesa antes não

\footnotetext{
* Professora Adjunta de Língua Portuguesa, no curso de Letras, do Centro de Professores da
} Universidade Federal do Recôncavo da Bahia, Amargosa, BA, Brasil; lisanasampaio@,ufrb.edu.br 
vislumbradas. Ensejando cenários de interdisciplinaridade, tal progresso tem dado suporte a investigações científicas em diversos âmbitos, despertando um interesse cada vez maior pelo desenvolvimento de técnicas que garantam o rigor e confirmem a precisão dos estudos elaborados ${ }^{1}$.

Os estudos linguísticos em perspectiva histórica, especificamente, passaram a demandar a incorporação desse desenvolvimento progressivamente e têm, hoje, lugar de destaque no uso de tecnologias que possam contribuir para facilitar o acesso às fontes documentais remanescentes - únicas testemunhas de que se possa servir o olhar atento de linguistas e filólogos - a partir dos acervos disponibilizados pelas bibliotecas digitais, o que tem sido determinante para possibilitar maior precisão no trabalho sobre a constituição histórica das línguas naturais e, em especial, do português.

Acervos digitais, como o da Biblioteca Nacional de Portugal, têm disponibilizado importantes obras para a história linguística do português, garantindo ao pesquisador interessado em investigar a constituição histórica da língua o conhecimento das fontes primárias, fundamentais para a aproximação de estágio passado de qualquer língua.

Vale ressaltar que, no esteio do que afirmou Mattos e Silva (2006; 2008), crêse que não é possível apreender a totalidade do passado, mas apenas dele "aproximar-se", pois por ser a realidade uma interpretação de um ponto de vista, será sempre inapreensível. Assim, para conhecer o português arcaico, conforme defende Mattos e Silva (2006, p. 33-48), é preciso conhecer a documentação escrita remanescente, seja pela leitura dos manuscritos existentes, seja por intermédio de edições.

Entre as obras disponíveis no referido acervo digital, consta o Cancioneiro Colocci-Brancuti (também conhecido como Cancioneiro da Biblioteca Nacional de Portugal), um dos três principais códices da produção trovadoresca, composta por mais dois cancioneiros galego-portugueses - Cancioneiro da Vaticana e o Cancioneiro da Ajuda - e pelos códices das Cantigas de Santa Maria - um conjunto representativo que há muito tem servido para análises literárias, fonético-fonológicas e para investigações acerca do comportamento morfossintático e semântico daquela língua poética.

O Cancioneiro da Biblioteca Nacional, por possuir o maior número de composições e, por conseguinte, registrar mais de 150 nomes de trovadores e cantigas, além da fragmentária Arte de Trovar, inexistentes nos outros cancioneiros, e fornecer ainda muitos elementos extratextuais que contribuem para a recomposição do cenário de recolha e compreensão do processo de construção, é considerado por muitos estudiosos, como atesta Ferrari (1993, p. 119), o mais importante dos códices da lírica galego-portuguesa, apresentando uma rica bibliografia.

\footnotetext{
${ }^{1}$ Como exemplos desses avaços tecnológicos, podem-se citar os corpora da língua portuguesa que têm sido disponibilizados, como o CETENFolha (<https://www.linguateca.pt/cetenfolha/ $>$ ), Corpus Histórico do português Tycho Bahe (disponível em: https://www.linguateca.pt/cetenfolha/), CoMET - Corpus Multilingue para Ensino e Traducão (disponível em < http://comet.fflch.usp.br/projeto >), o Corpus Eletrônico de Documentos do Sertão (disponível em: http://www5.uefs.br/cedohs/view/tutorial.html e a disponibilização de software para análise de corpus como o fez o Grupo de Morfologia Histórica do Português (cf. site < http://www.usp.br/gmhp/soft.html >).
} 
Os muitos estudos produzidos a partir desse corpus ${ }^{2}$ têm ratificado sua importância e indicado a necessidade de investigação de alguns aspectos que ainda não foram devidamente explorados, sobretudo no que concerne ao léxico, nível de análise linguística em que as mudanças socioculturais se evidenciam mais clara e imediatamente.

Nesse sentido, o presente estudo concentra-se na apresentação do processo de elaboração de uma edição diplomática das cantigas satíricas do Cancioneiro da Biblioteca Nacional (ou Colocci-Brancuti) para composição de um vocabulário das formas verbais, finitas e infinitivas, patentes nessas cantigas, produzido a partir dos preceitos da Lexicografia histórica, ressaltando a importância do acesso à documentação remanescente a partir do acervo digital disponibilizado pela Biblioteca Nacional de Portugal, o que permitiu a observação da riqueza dos dados linguísticos desse códice e a preservação de todos os aspectos que possam dar pistas para a investigação e registro da língua patente nesses fragmentos do tempo.

Note-se que as reflexões apresentadas resultaram da pesquisa de doutorado concluída em 2018, no programa de Pós-Graduação em Língua e Cultura, da Universidade Federal da Bahia, a qual teve o escopo a elaboração de uma edição diplomática das cantigas satíricas do Cancioneiro da Biblioteca Nacional e de um vocabulário das formas verbais finitas e infinitivas patentes nessas composições a partir dos preceitos da Lexicografia Histórica, com vistas a contribuir com o trabalho de reconstrução da trajetória da língua portuguesa no período arcaico, objetivo principal do projeto Dicionário Etimológico do Português Arcaico (Projeto DEPARC), de longa duração, em andamento na Universidade Federal da Bahia, a que se filia.

Um dos projetos do Grupo de Pesquisa Nêmesis, dedicado aos estudos do léxico e da história da língua portuguesa, o DEPARC tem por objetivo elaborar, como o próprio nome sugere, um Dicionário Etimológico do Português Arcaico, nomeadamente sobre o arco temporal compreendido entre os séculos XIII e meados do XVI. Registre-se que o projeto é apoiado pelo Conselho Nacional de Pesquisa e Desenvolvimento Tecnológico - CNPq e que a sua primeira edição foi publicada em $2013^{3}$.

\section{SOBRE AS CANTIGAS SATÍRICAS DO CANCIONEIRO DA BIBLIOTECA NACIONAL: CONTEXTUALIZANDO O CORPUS DE PESQUISA}

A investigação dos processos de produção, transmissão e recepção dos corpora remanescentes é fundamental para que se possa alcançar um bom resultado na "arte de fazer o melhor uso de maus dados", como bem definiu Labov (1982, p. 20) os estudos da mudança linguística em perspectiva diacrônica.

Para compreender o corpus selecionado para o desenvolvimento da pesquisa ora apresentada, vale registrar, em linhas gerais, sua base teórica, ou seja, um panorama da lírica trovadoresca.

\footnotetext{
2 Muitos estudos elaborados a partir do Cancioneiro da Biblioteca Nacional, como os trabalhos de Machado; Machado (1949-1964), Tavani (1999) e Ferrari (1979).

3 Para saber mais do Projeto DEPARC, cf. o site do Grupo de Pesquisa Nêmesis <https://gruponemesis.ufba.br/>.
} 
Nesse sentido, note-se que o movimento literário que emergiu no cenário hispânico na virada dos séculos XII e XIII tem desafiado diversos estudiosos que se dedicam a perscrutar as fases pretéritas desenroladas no ocidente peninsular, uma vez que somente três testemunhos dessa produção conseguiram atravessar os reveses do tempo e transmitir fragmentos desse episódio da história, o Cancioneiro da Ajuda, o Cancioneiro da Biblioteca Nacional e o Cancioneiro da Vaticana ${ }^{45}$.

Esse movimento cultural que mais tarde ficou conhecido como Trovadorismo foi responsável pela elaboração de uma nova concepção de amor (a fin'amor ou amor cortês), pela inauguração de uma maneira original de fazer poesia e, sobretudo no século XII, pela produção do que se convencionou denominar lírica trovadoresca ${ }^{6}$ (Tavani, 2002, p. 9-10).

Exportada pelos próprios trovadores e jograis provençais fora dos confins geopolíticos da Occitânia, como explica Tavani,

\begin{abstract}
essa lírica serviu de modelo a poetas naturais das diferentes regiões da Europa Central e Ocidental: mas enquanto alguns, por contiguidade geográfica, afinidade de estruturas sociopolíticas e analogias entre as respectivas formas de expressão - como no caso dos «lombardos» da Itália Setentrional e dos catalães - adoptaram, juntamente com os parâmetros temáticos e as estruturas técnicas da nova poesia, também a língua dos «mestres», os outros, todos os outros - os trouvères franceses, os Minnesänger alemães e os trovadores, segréis e jograis hispânicos tiveram que adaptar o modelo aos hábitos, às exigências e às tradições culturais das sociedades às quais pertenciam. (Tavani, 2002, p. 10).
\end{abstract}

A inspiração provençal, em simbiose com a tradição e língua locais, culminou no desenvolvimento de uma lírica muito peculiar para os públicos periféricos. No noroeste da Península Ibérica, a lírica galego-portuguesa, produzida nas cortes senhoriais e régias, foi transmitida aos dias atuais por mais de mil e seiscentos textos contidos nos cancioneiros remanescentes (Lindeza Diogo, 1998, p. 11).

Concebida originalmente em fólios individuais por cantiga, essa lírica cortês peninsular era executada para as cortes reais, as quais tiveram notável importância no seu acolhimento e difusão, e para as cortes senhoriais, principais responsáveis pela sua implantação na Península.

A produção era musicada e classificada em gêneros definidos como cantigas de amor, cantigas de amigo, cantigas de escárnio e maldizer, prantos, sirventeses, tenções etc. pelos seus próprios agentes que são designados uns por trovadores, outros por jograis.

Entre as cortes régias de Leão, Castela, Portugal e de algumas casas senhoriais de outras regiões, um conjunto vasto e diversificado de trovadores produziu essa

${ }^{4}$ Além desses três cancioneiros, há também o Pergaminho Vindel - descoberto no século XX -, o Pergaminho Sharrer - descoberto nos inícios dos anos 90 (Cf. Oliveira, 1995) e o Cancioneiro da Bancroft Library, "conhecido, no século XIX, como o Cancioneiro de um Grande d'Hespanha, que é uma cópia lacunosa do Cancioneiro da Vaticana” (Souza, 2012, p. 569).

${ }^{5}$ Note-se que o cancioneiro mariano não é considerado no corpus da lírica galego-portuguesa, pois adota-se aqui a posição defendida por Tavani (1986) e Lindeza Diogo (1998) de que "as Cantigas de Santa Maria integram outras tradições".

6 Para maior conhecimento dos produtos literários que costumam ser designados como lírica trovadoresca, ver Tavani (2002). 
arte. Além de exercer o papel de incentivadores e protetores desses poetas, homens de poder, como o rei Afonso X e o seu neto D. Dinis, foram, muitas vezes, exponenciais autores de cantigas ${ }^{7}$.

$\mathrm{Na}$ segunda metade do século XIII, as compilações foram produzidas seguindo normas de organização atentas à condição social dos compositores, o que acabava por evidenciar o que já era visível na imagem que as cantigas de escárnio projetavam sobre a separação entre o trovador e o jogral e, também, sobre a superioridade artística do primeiro, validada pelas maiores exigências da composição perante o canto ou o acompanhamento instrumental, do segundo (Oliveira, 1995, p. $45)$.

O registro dessa produção remonta à atividade cultural de D. Pedro Afonso, conde de Barcelos, o qual, ao longo da primeira metade do século XIV, desenvolveu uma vasta tarefa de recolha e organização de textos literários diversos que resultaram na confecção do chamado Livro de Linhagens do conde D. Pedro, da Crónica Geral de Espanha de 1344 e do Livro das Cantigas, este mencionado no seu testamento de 1350, mas, até então, não encontrado.

No entanto, conforme defende Oliveira (1994), a "preservação das cantigas através da escrita surge associada à consciência do provável esquecimento ou desaparecimento das mesmas, caso se mantivessem vinculadas às condições de transmissão da manifestação cultural em que se encontravam inseridas" (Oliveira, 1994, p. 13).

Como mencionado, restam apenas três grandes compilações para o conhecimento da canção trovadoresca, as quais são cópias elaboradas em dois diferentes momentos, o primeiro deles, foi copiado no século XIII e representado pelo Cancioneiro da Ajuda, e o outro momento pelo Cancioneiro da Biblioteca Nacional e pelo Cancioneiro da Vaticana, copiados no início do século XVI, na Itália.

Assim como a origem dessa rica lírica resta ainda no domínio das especulações, pressupõe-se também que deve ter existido uma poesia galegoportuguesa anterior às composições, que se têm conservado nos códices remanescentes, e a atividade trovadoresca, provavelmente, seguiu florescendo até meados do século XIV (Scholberg, 1975, p. 50).

Gonçalves (1985) resume a lírica galego-portuguesa da seguinte forma:

Um grupo de cerca de $1680^{8}$ textos de assunto profano transmitidos por três cancioneiros manuscritos [...], todos eles produzidos numa língua bastante uniforme, o galego-português, num período que vai de finais do século XII à segunda metade do século XIV. Com exceção de alguns que continuam anónimos, os textos dos Cancioneiros profanos são atribuídos a 153 trovadores e jograis: reis, senhores de alto linhage, clérigos ou simples filhos do povo que, competindo com a classe nobre, a igualam, muitas vezes, no plano técnico-artístico. A língua poética une, de resto, poetas não apenas galegos ou portugueses, como poderia parecer, mas castelhanos, leoneses ou mesmo extra-peninsulares, que, por «exotismo» ou simpatia profissional, a escolheram para cantar o amor «ou dizer mal de alguém», isto é, para comporem cantigas de amor, cantigas de amigo ou cantigas de escárnio e mal dizer. (Gonçalves, 1985, p. 18-19).

\footnotetext{
7 Para um amplo conhecimento dos agentes culturais do espetáculo trovadoresco ver Oliveira (1995).

${ }^{8}$ Cf. Tavani; D’Heur para conhecimento da questão do número exato de cantigas.
} 
Embora um tanto simplista, uma vez que foi formulada como introdução de uma antologia, a descrição de Gonçalves é razoavelmente ilustrativa para a compreensão geral do cenário trovadoresco.

Ademais, a autora chega a advertir que "a língua uniforme", a que se referiu, não se traduz, efetivamente, nos cancioneiros, em razão dos próprios gêneros das compilações, que se submeteram a copistas que, por vezes, se condicionaram à língua que copiavam, criando, para a história, os problemas de interpretação que, até, hoje persistem.

A repartição por gêneros é uma das "características tipológicas mais imediata e concretamente identificável na poesia lírica galego-portuguesa" (Tavani, 2002, p. 131). No entanto, para além desses gêneros, o Cancioneiro da Biblioteca Nacional inclui ainda um tratado de poética, comumente, intitulado Arte de Trovar ${ }^{9}$, no qual se explicitam os gêneros maiores, dos quais as cantigas de amor e de amigo são as primeiras, seguidas da distinção entre as cantigas de escárnio e de maldizer, e das características dos gêneros menores.

$\mathrm{Na}$ Arte de Trovar, as orientações para classificação das cantigas de escárnio como "aquelas que os trovadores fazem, querendo dizer mal de alguém", utilizando palavras cobertas no sentido de que haja ambiguidade (denominada pelos "clérigos" de equivocatio) e que o entendimento não seja imediato, em contraponto às cantiga de maldizer, como a cantiga em que o trovador fala mal "descobertamente", garantindo que a ofensa seja compreendida, são categoricamente uma evidência de que esse texto sobre a poética não se constitui como princípio dos cancioneiros profanos.

A imprecisão da adoção da terminologia escárnio e maldiz̧er se torna ainda maior se os demais gêneros forem observados mais atentamente.

Como explicam Lanciani e Tavani,

tanto as cantigas de amor como as de amigo sempre se reconhecem como tais em função de um número finito e bem caracterizado de conotadores; por isso, quase sempre é possível (e, na maioria das vezes, bastante cômodo) agrupá-las em conjuntos orgânicos que, embora sejam muito vastos, apresentam-se claramente marcados, mesmo se contrastados por fórmulas bem precisas [...]. Pelo contrário, quando se fala de cantiga de escárnio e maldizer, faz-se uma referência ambígua a um coacervo de textos frequentemente muito diversos entre si, desde o canto a temas e modulações tonais. (Lanciani; Tavani, 1995, p. 7. tradução nossa) ${ }^{10}$.

Nesse sentido, advoga-se que em lugar dos termos vacilantes escárnio e maldižer, para os textos que definitivamente não sejam de amor ou de amigo,

\footnotetext{
9 Texto lacunar e pouco preciso que, segundo alguns autores, foi, arbitrariamente, eleito como um fascículo introdutório para o exemplar do Cancioneiro da Biblioteca Nacional trabalhado por Colocci (Ferrari, 1979, p. 93).

10 "Tanto as cantigas de amor como as cantigas de amigo sempre se recoñecen como tales en función dun número finito e ben caracterizado de connotadores; por isso resulta case sempre posible (e as mais das vezes bastante cómodo) agrupalas en conxuntos orgánicos que, malia seren moi vastos, preséntanse sen embargo claramente marcados, mesmo se diria que contrastados por fórmulas ben precisas [...]. Pola contra, cando se fala de cantiga de escárnio e maldicir, faise ambigua referencia a un coacervo de textos con frecuencia moi diversos entre si en canto a temas e modulacións tonais." (Lanciani; Tavani, 1995, p. 7).
} 
empregue-se a terminologia gênero satírico, a qual englobaria todos os textos que elaborem uma crítica dirigida a alguém, ou movida pelos mais diversos personagens e acontecimentos sociais, com o intuito de provocar a troça, fazer uma denúncia, combater um comportamento.

A anterior adoção terminológica desse gênero que causou, historicamente, uma imprecisão justifica-se, provavelmente, pela insegurança classificatória dos estudiosos desse material, em função ainda das oscilações presentes nessa tradição manuscrita devido a atitudes equivocadas dos compiladores da coleção primitiva. Por essa razão, todas as poesias líricas galego-portuguesas que não são classificáveis dentro do registro amoroso foram agrupadas sob a etiqueta escárnio e maldizer (Lanciani; Tavani, 1995, p. 8).

Observando a riqueza lexical desse gênero representado por 403 (quatrocentas e três) cantigas, de um total de 1664 (mil seiscentas e sessenta e quatro) cantigas patentes no Cancioneiro da Biblioteca Nacional, considera-se que o recorte do gênero em um dos cancioneiros fundamenta-se em sua alegada representatividade e completude em comparação com os demais manuscritos.

Nesse fôlego, ao longo do processo de seleção e edição das cantigas, notou-se que há uma demanda crescente de trabalhos de pesquisa que se voltem ao levantamento, observação e inventariação das unidades lexicais patentes nesses corpora para recomposição da história da língua portuguesa.

\section{ELABORAÇÃO DE UMA EDIÇÃO DAS CANTIGAS SATÍRICAS DO CANCIONEIRO DA BIBLIOTECA NACIONAL PARA O ESTUDO DO LÉXICO: ENTRE O LABOR FILOLÓGICO E O MÉTODO DA LEXICOGRAFIA HISTÓRICA}

Diante da documentação remanescente, o pesquisador, à guisa de um arqueólogo da língua, deve cautelosamente recuperar, por meio do trabalho filológico, a língua registrada nesse espólio, interpretando o seu processo de constituição histórica a partir dos dados depreendidos desses textos.

No âmbito dos estudos linguísticos, assume-se que a Filologia seja uma ciência dedicada aos aspectos da materialidade, produção, transmissão e recepção do texto, e, conforme assevera Mattos e Silva (2008, p. 14), "parece integrar-se melhor como uma das formas de abordar a documentação escrita, tanto literária como documental".

De forma muito ampla, Auerbach define a Filologia como "o conjunto das atividades que se ocupam metodicamente da linguagem do Homem e das obras de artes escritas nessa linguagem" (Auerbach, 1972, p. 11). Essa definição é muito próxima da que se encontra em Telles, para quem essa ciência "se ocupa da linguagem do homem", e, "portanto, com a sua forma de expressão viva, variável. Ocupa-se também com as obras de arte (os textos literários) plasmados nessa linguagem" (Telles, 2016, p. 22).

É assim Filologia uma ciência interpretativa que estabelece uma íntima relação com a Linguística Histórica, já que

para obter conhecimentos sobre a língua de épocas anteriores e para explicar processos históricos de mudança, carece de dados registados nos textos escritos: para a investigação em perspectiva diacrônica, é 
absolutamente necessária uma consistente infra-estrutura filológica e uma sólida preparação por parte do investigador que lhe permita uma interpretação dos textos escritos que constituem o seu corpus de análise adequada. (Maia, 2012, p. 537).

A fixação, anotação e preparação do texto para análises linguísticas devem ser realizadas, observando "certas normas capazes de assegurar que fique intacta a fase linguística espelhada na obra" (Silva Neto, 1956, p. 22), com rigor filológico e com o objetivo claro de servir a estudos dessa natureza (Matos e Silva, 2008, p. 15).

Hoje, é possível fotografar, copiar ou digitalizar mecanicamente esses manuscritos, o que elimina o eminente risco de erro dos copistas e aumenta a segurança e divulgação dos textos antigos.

Todavia, para lidar diretamente com as imagens dos manuscritos, é preciso compreender sua história e suas peculiaridades codicológicas, interpretar corretamente sua escrita, baseando-se nos preceitos de outra ciência filológica, a Paleografia, que se firmou como disciplina auxiliar da edição de textos, com o fito de habilitar os pesquisadores a decifrar os caracteres, as abreviaturas em uso e qualquer indício material que possa contribuir para a recuperação mais fidedigna possível do passado distante (Auerbach, 1972, p. 17). É de mais ainda fundamental importância esse conhecimento para o trabalho de transcrição e restabelecimento de textos.

A Filologia, como assevera Cunha (2004, p. 344), mantém com a obra literária uma permanente ligação, no que concerne à documentação remanescente, mormente à lírica profana galego-portuguesa, visto que há um número expressivo de edições elaboradas a partir desse espólio.

Todavia, as edições realizadas das 1664 cantigas transmitidas pelos únicos testemunhos conhecidos, em sua maioria, têm o intuito de divulgar a produção trovadoresca para um público amplo. Essas edições são elaboradas a partir de um comportamento editorial modernizador, com um maior grau de intervenção no que concerne à regularização de nasais, atualização da pontuação e da acentuação, quebra de linhas e restituição textual.

Tais trabalhos, embora estabeleçam alegadamente textos ideais para o conhecimento dos temas das cantigas, dos gêneros literários, dos trovadores e do contexto histórico, não deixam transparecer os dados linguísticos que tanto podem contribuir para o conhecimento do léxico da época, dos traços fonéticos, fonológicos e morfológicos - já que a sintaxe é comumente pouco afetada na modernização dos textos.

Entre as edições mais conhecidas, pode-se citar a edição crítica do Cancioneiro da Ajuda, elaborada em 1904, por Carolina Michaëlis de Vasconcelos e as edições das cantigas por trovador: Les chansons de Pero Garcia Burgalês Troubadour Galicien-Portugais Du XIII ${ }^{\circ}$ Siècle, de Pierre Basco (1964); Pero da Ponte: Poesias, de Saverio Panunzio (1967); As poesias de Martin Soares, de Valeria Bertolucci Pizzorusso (1963); Martin Moya, la poesie, de Luciana Stegano Picchio (1968); El cancionero de Joan Airas de Santiago, de José Luis Rodriguez (1980) e as edições elaboradas a partir dos três grandes gêneros, como a edição das Cantigas d'Escarnho e Maldizer dos Cancioneiros Medievais Galego-portugueses, de Manuel Rodrigues Lapa, cuja primeira impressão data de 1965, e a segunda de 1970. 
Os muitos estudos realizados ratificam a importância do documento para a investigação da constituição da língua portuguesa por um lado e, por outro, apontam para possibilidade de outras incursões, sobretudo, no que concerne aos estudos sistemáticos que promovam o registro do léxico patente nesses corpora de acordo com os preceitos da Lexicografia Histórica, pois a observação e a sistematização do léxico dessas coletâneas trovadorescas ainda estão na agenda de investigações que devam ser empreendidas.

A observação da riqueza dos dados linguísticos desses códices demanda uma singular atenção no tratamento dos textos, a fim de preservar todos os aspectos que possam dar pistas para a investigação e registro da língua patente nas cantigas trovadorescas.

Nessa perspectiva, tem-se preconizado que a transcrição de textos antigos, quando destinada a estudos de caráter linguístico, deve ser "extremamente fidedigna e cuidadosa", permitindo transparecer "os traços fonológicos e fonéticos visíveis nos originais manuscritos" (Maia, 1986, p. 19).

Tal posição está na base dos métodos adotados pela lexicografia histórica, a qual, conforme define Machado Filho (2012), é

\begin{abstract}
um campo de pesquisa deveras idiossincrático, já que, diferentemente da lexicografia contemporânea, a conservação da diversidade de usos da escrita, isto é, o pleno registro da variação gráfica, é muito mais requerido naquela do que nesta, passando essa ideia a se configurar como uma das linhas metodológicas norteadoras do trabalho de pesquisa diacrônico do léxico, nomeadamente no que se refere à construção de dicionários históricos da língua, em especial daqueles que objetivem registrar o período que antecede as novas posturas sociais, comportamentais e linguísticas do período renascentista em Portugal. (Machado Filho, 2012, p. 382).
\end{abstract}

Estabelecendo métodos que destoam significativamente dos ditames tradicionais da lexicografia contemporânea, a fundação dessa vertente lexicográfica, ou seja, da Lexicografia histórico-variacional, vem como resposta à pouca atenção que a Lexicografia tradicional tem dado aos formatos lexicais que se dissociam dos padrões linguísticos adotados hodiernamente. Isto é, as realizações lexicais patentes na fala de diferentes dialetos brasileiros não têm conseguido o registro que a história deveria promover, haja visto que,

\footnotetext{
no que concerne ao léxico, desconhecem-se ou omitem-se, como produtos linguístico-culturais de importância para a compreensão do processo formativo da língua, os formatos morfofônicos dos metaplasmos tão comuns desde a passagem do latim para o português, tais como próteses ou aféreses, epênteses ou síncopes, paragoges ou apócopes, rotacismos etc., muitas vezes desprezados no processo de registro escrito da história linguística do País. Considerando que verba volant, é tempo de se evitarem as perdas a que se submeteram as línguas naturais, no que concerne às formas linguísticas das minorias no processo de construção das línguas de cultura. [...] mas já seria tempo de se estabelecerem estratégias pontuais que possam reverter, ao menos, parcialmente, a assepsia imposta pela norma-padrão aos formatos linguístico-lexicais dissonantes. (Machado Filho, 2014, p. 244).
} 
Nesse sentido, a edição elaborada procurou dar conta da realidade da língua do códice, descartando a possibilidade de emendar o texto para recuperar a rima e o sentido, atitude muito comum nas edições direcionadas aos estudos literários. Assim, o grande exercício foi a produção desse novo material que tanto servirá de consulta para outros pesquisadores, quanto continuará como foco de interesse na investigação de cunho lexicográfico.

Observou-se, na vasta bibliografia consultada, que há uma obstinada busca pelo sentido de cada cantiga, o que tem culminado em uma reconstituição textual que tem comprometido o conhecimento dos usos linguísticos da época.

Em uma das mais recentes edições dessas cantigas, construída a partir de 2011, por Lopes e sua equipa, no projeto Littera, desenvolvido na Universidade Nova de Lisboa, notam-se diversas ocorrências em que o texto estabelecido não corresponde ao registro do códice, como exemplificado nas figuras a seguir:

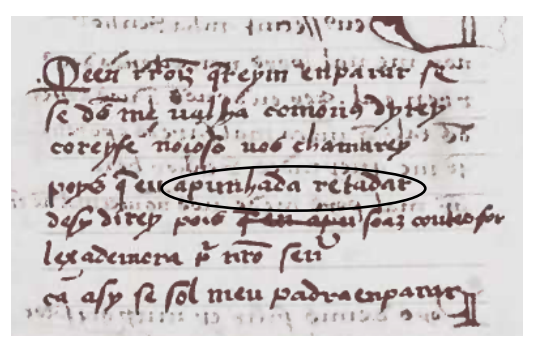

Fonte: Códice do Cancioneiro da Biblioteca Nacional

Figura 1 - Excerto do fólio 90rC1.

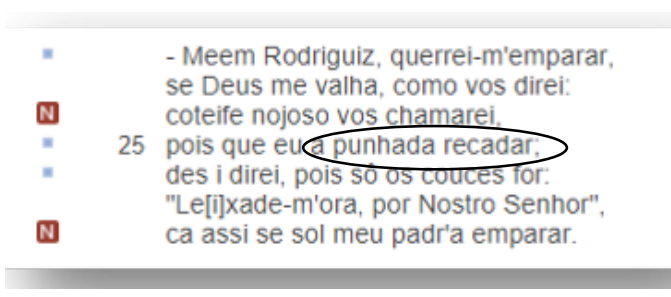

Fonte: Lopes (2011)

Figura 2 - Excerto da edição da cantiga de n 403 (tenção) elaborada por Lopes (2011).

Como é possível observar, a leitura (figura 2) proposta corrige o que é julgado como provável erro do copista ou erro do exemplar de cópia (figura 1), criando para a história dados inexistentes ou deixando de registrar fatos linguísticos e, consequentemente, informações sócio-históricas.

$\mathrm{Na}$ transcrição da estrofe apresentada na figura 1, manteve-se o que foi possível ler no códice, apontando-se em nota soluções interpretativas de propostas por outros editores com o escopo de colaborar para a recuperação do sentido da poesia.

Observe-se, na figura abaixo, a transcrição da referida estrofe:

\section{Meen rrodriguiz quereym enparar se 23 . se deus me ualha como uos dyrey \\ 24. coreyfe noioso uos chamarey \\ 25 . poys que elapunhada retadars \\ 26 . desy direy pois soaz coutes for ${ }^{58}$ \\ 27. lexademora por nostro senhor \\ 28. ca asy se sol meu padra enparar ${ }^{59}$}

Fonte: Sampaio (2018)

Figura 3 - Excerto da edição da cantiga de no 403 (tenção). 
Embora a falta de logicidade do verso da linha 25 não contribua para a compreensão da cantiga, considerando os interesses da presente pesquisa, não é coerente criar um fenômeno linguístico, visto que, no trabalho de investigação linguística, soluções ad hoc para resolução de problemas de texto não podem ser admitidas. Nesses casos, é preferível não ter a segurança da leitura do que ter uma leitura engendradada para aproveitar a "materialidade histórica" desses textos poéticos.

Salienta-se, no entanto, que as edições das cantigas satíricas elaboradas com intuito de divulgar os temas das cantigas têm contribuído significativamente para a divulgação dessa documentação literária e para o conhecimento das histórias registradas nos motivos desse espólio.

A sistematização das formas verbais finitas e infinitivas a partir dos preceitos metodológicos da lexicografia histórica exigiu redobrado cuidado e atenção na recolha e anotação de alguns itens lexicais no que concerne à apresentação do étimo, definição e determinação do tempo, modo e pessoa verbais.

Embora nas últimas décadas tenha havido um notável avanço tecnológico, como mencionado no início deste texto, despertando um interesse cada vez maior pelo desenvolvimento de técnicas que garantam o rigor e confirmem a precisão dos estudos elaborados, notou-se, na consecução do trabalho de cunho lexicográfico, que os programas informatizados disponíveis dificilmente serviriam para a construção do glossário em virtude dos seus limites de leitura de caracteres.

Programas como o WordSmith que têm contribuído significativamente para a lexicografia moderna, fragmentador/concordanciador publicado pela Oxford University Press, vêm sendo utilizados em trabalhos de análises lexicais, nos quais além de fragmentar os corpora em wordlists, apresentam ferramentas para realizar a contagem de frequência, agrupar variações, destacar palavras de acordo com o uso, fornecer estatísticas e concordâncias de forma fácil e flexível, não puderam ser aproveitados na composição do glossário.

O seguro levantamento das formas verbais patentes no corpus só foi possível a partir de uma leitura atenta e precisa do fac-símile do Cancioneiro da Biblioteca Nacional. Nessa etapa do processo, a análise dos padrões lexicais dos verbos e a identificação das colocações a eles relacionadas, assim como, a avaliação do comportamento morfossintático dos lemas selecionados, modos, tempos e pessoas verbais para definição dos itens abonativos da microestrutura foram realizadas com muita atenção aos textos poéticos.

A identificação de formas verbais que estavam grafadas com fronteiras de espaço, como a do acertar, por exemplo, apresentada na figura a seguir, demandou uma leitura cuidadosa das cantigas estudadas, uma vez que se conservaram, na edição elaborada, todos os aspectos grafemáticos e vocabulares.

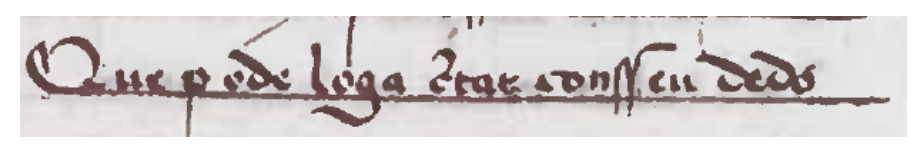

Fonte: Códice do Cancioneiro da Biblioteca Nacional

Figura 4 - Excerto do fólio F280vC2. 
Buscou-se também traçar um contraponto entre a perda de informações que estão no radical (no léxico) e a manutenção de informações morfológicas. Formas como maer, gaar, emparar, entre outras, caíram em completo desuso no português atual e, por essa razão, a recuperação da informação semântica reclamou um cuidadoso trabalho interpretativo.

Além disso, a frequência de alguns itens foi um dos fatores que dificultaram a sistematização dessas formas. Alguns verbos ocorreram apenas uma vez, no infinitivo, como o verbo ambrar e, como é comum à poesia, não é possível recuperar com segurança o seu sentido com base em apenas uma ocorrência.

Adotaram-se, então, estratégias remissivas, relacionando os verbos a partir dos seus traços significativos, como ilustrado na figura a seguir:

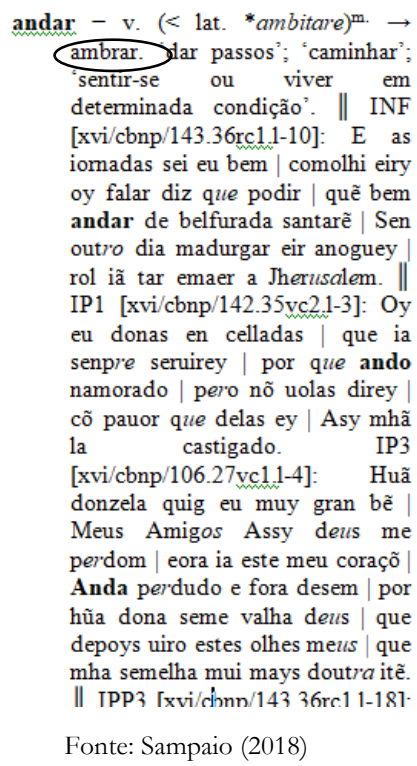

Figura 5 - Excerto do Glossário.

Como nem sempre foi possível recuperar, com base em uma única ocorrência, o sentido do verbo, adotou-se, nesses casos especificamente, a solução do trabalho lexicográfico mais recente dessas cantigas, como o exemplo do verbo arar, definido por Lopes (2011-), como 'esforçar-se em vão', não comportando o significado de 'sulcar'; 'cultivar a terra', conforme o uso no português atual.

Por questões de métrica, na poesia, às vezes, há o apagamento do morfema número-pessoa e nas ocorrências em que a informação morfológica não é mantida, como em um dos exemplos da primeira pessoa do Presente do Indicativo do verbo entender, no qual só é possível reconhecer esse morfema pelo contexto ou pela explicitação do sujeito. 


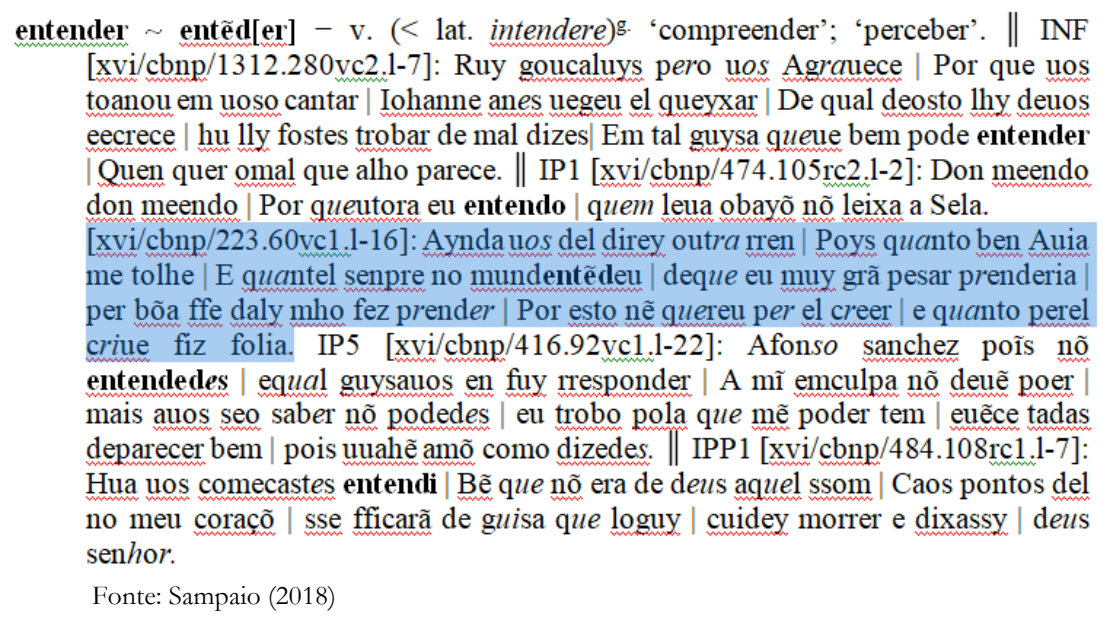

Figura 6 - Excerto do Glossário.

Houve também verbos que ocorreram apenas uma vez em uma forma finita, como o verbo faronei [ar] que só ocorre no Presente do Indicativo e não está registrado nos dicionários etimológicos, nem latinos, consultados. Há, no entanto, a possibilidade interpretativa de aproximá-lo do verbo farejar que não ocorre no corpus, mas tem um amplo uso nas variantes lusófonas.

faronei[ar] - v. (etimologia obscura. Talvez de faro) ${ }^{\mathrm{m}}$. 'intuir?'. $\|$ IP3 [xvi/cnbp/494.110rc2.1-4]: O que foy passar a Serra | e nõ quis sseruir aterra | e ora entrara guerra $\mid$ que faroneia $\mid$ pois el ago ratan muito erra $\mid$ mal dito seia.

Fonte: Sampaio (2018)

Figura 7 - Excerto do Glossário.

Muitos verbos, conforme previsto, caíram em total desuso e só puderam ser registrados por meio do trabalho de natureza histórica que tem sido elaborado há décadas e pela criteriosa leitura dos contextos disponíveis. Verbos como chufar, maer, com o sentido de 'zombar'; 'pernoitar'; respectivamente, presentes no corpus selecionado, caíram em total desuso e já não podem ser reconhecidos como unidades da língua pelo falante contemporâneo.

Vale registrar que é preciso que o lexicógrafo histórico-variacional desenvolva métodos próprios que referendem atualmente elementos olvidados na passividade do passado e, por essa razão, é preciso considerar as demandas por reflexões maiores acerca do léxico, sua unidade de comportamento e seus desdobramentos teóricos.

\section{CONSIDERAÇÕES FINAIS}

As investigações dos códices cancioneirísticos têm evidenciado os desafios desse empreendimento, posto que as dificuldades se tornam ainda maiores somadas à complexidade de diversas questões acerca desses códices. 
Essa documentação é importante para a história linguística do português, pois testemunha as mais antigas manifestações literárias conhecidas e, portanto, cabe ao pesquisador interessado nesses registros assegurar o lugar do que se encontra velado, descrevendo com a acuidade e a precisão possíveis o material disponível para o conhecimento da constituição histórica das línguas.

Nessa perspectiva, o olhar atento para os três gêneros dessa produção trovadoresca, sobretudo no que concerne às estruturas verbais, exibem no seu espólio documental um comportamento deveras singular, seja no plano morfológico, seja no plano semântico.

Machado Filho, em vários trabalhos, já havia alertado para a necessidade de inventariação do comportamento gramatical dos verbos no português, chegando a afirmar que essas unidades da língua demonstram "um comportamento flexional bastante prolífico e produtivo na história da escrita" (Machado Filho, 2012, p. 382), apresentando-se como uma importante fonte para a ampliação do conhecimento do processo de constituição histórica da língua portuguesa.

O seu Dicionário etimológico do português arcaico (2013) é prova disso, já que resgata formatos morfológicos e valores semânticos bastante prolíficos nesse período da língua, conquanto muito inusitados para os padrões de uso hodiernos.

Sua posição comprova-se, por exemplo, em textos mesmo do século XV, quando a língua já caminhava para uma configuração que viria a representar o português moderno. No Livro dos Usos da Ordem de Cister, desse período, editado por Sampaio, em 2013, existem fartos exemplos disso, como no pequeno fragmento abaixo destacado do fólio $73 \mathrm{r}$ da obra:

E des aly. I podem os sangrados. tã bem em tempo de liçõ come de lauor./ iazer | em seos leitos. ou seer no cabidoo. e na claustra./ ataa que | entrem ao coro. Semelhauilmente. o que steuer fora do coro. nõ | lea nem cante. (Sampaio, 2014, p. 161).

Vê-se claramente que os verbos jazer e ser para além de apresentarem grafias etimologizantes, conservam seus valores originais de 'estar deitado' e 'estar sentado', respectivamente, que foram posteriormente alterados para 'estar morto' e 'existir'.

Se se utilizassem esses verbos no Imperfeito do modo Indicativo, em terceira pessoa do discurso, por exemplo, haver-se-ia de constatar que seus formatos deveriam ser nesse momento os de iazia e siia, sendo este último completamente desconhecido na contemporaneidade, já que foi substituído por era, derivado do verbo latino esse, como se sabe.

Isso prova a importância de se promoverem trabalhos de pesquisa que se voltem ao levantamento, observação e inventariação dessas unidades lexicais para recomposição da história da língua portuguesa.

Como demonstrado, formas verbais finitas e infinitivas como oi, jaq, maer (B143); avilastes, gaar (B1585); emparar (B1585); fal (B 1636); avém, baralha (B1645); terrei, ementam (B1650) etc., comprovam seu valor histórico-linguístico para a recomposição do cenário dos verbos em uso no período arcaico do português.

Nesse sentido, ratifica-se neste trabalho que o conhecimento do vocabulário específico do Cancioneiro da Biblioteca Nacional é, dado o seu valor testemunhal, uma 
importante empresa para a investigação da constituição histórica do português e que o estudo e a sistematização do léxico em perspectiva histórica devem nortear-se pelos pressupostos da Lexicografia Histórica.

Por fim, na seleção do corpus, validam-se as contribuições para o estudo linguístico desses textos poéticos medievais, em perspectiva histórica, para a pesquisa sobre o passado da língua portuguesa.

\section{REFERÊNCIAS}

Auerbach E. Introdução aos estudos literários. Tradução José Paulo Paes. 4. ed. São Paulo: Cultrix; 1972.

Cancioneiro da Ajuda. Edição fac-similada do códice existente na Biblioteca da Ajuda. Lisboa: Távola Redonda/Instituto Português do Patrimônio Arquitetónico e Arqueológico/Biblioteca da Ajuda; 1994.

Cancioneiro da Biblioteca Nacional (Colocci-Brancuti) Cód. 10991. Reprodução fac-similada com apresentação de Lindley F. Cintra. Lisboa: Biblioteca Nacional/Imprensa Nacional-Casa da Moeda; 1982.

Cancioneiro Português da Biblioteca Vaticana (Cód. 4803). Rep. fac-similada com introdução de Luís F. Lindley Cintra. Lisboa: Centro de Estudos Filológicos/Instituto de Alta Cultura; 1973.

Cunha C. Sob a pele das palavras. 1 ed. Rio de Janeiro: Nova Fronteira; 2004.

Ferrari A. Formazione e struttura del Canzoniere Portoghese della Biblioteca Nazionale di Lisbona (Cod. 10991: Colocci-Brancuti). In: Arquivos do Centro Cultural Portugués, XIV, Paris, Fundação Calouste Gulbenkian; 1979.

Ferrari A. Cancioneiro da Biblioteca Nacional. In: Lanciani G, Tavani G (org.). Dicionário da Literatura Medieval Galega e Portuguesa. Lisboa: Editorial Caminho; 1993.

Gonçalves E, Ramos MA. A lírica galego-portuguesa (textos escolhidos). Lisboa: Editorial Comunicação; 1985.

Lanciani G, Tavani G, organizadores. Dicionário da Literatura Medieval Galega e Portuguesa. Lisboa: Editorial Caminho; 1993.

Labov W. Building on the empirical foundations. In: Lehmann W, Malkiel Y. (eds) Perspectives on historical linguistics. Amsterdam/Philadelphia: J. B. Publishing Company; 1982. p. 17-92.

Lindeza Diogo AA. Lírica Galego-Portuguesa: Antologia. Braga-Coimbra: Angelus Novus; 1998.

Lapa MR. Cantigas d'Escarnho e de Maldizer dos Cancioneiros Medievais Galego-Portugueses, $2^{\mathrm{a}}$ Edição. Vigo: Editorial Galaxia; 1970.

Lapa MR. Cantigas d'Escarnho e de Maldizer dos Cancioneiros Medievais Galego-Portugueses, Coimbra: Editorial Galaxia. Ed. crítica; 1965.

Lorenzo R. Normas para a edição de textos medievais galegos. In: Actes du XVII ${ }^{a}$ Congrès International de Linguistique et de Philologie Romanes (Trier, 1986). Publiès par Dieter Kremer. Tübinger, Max Niemeyer Verlag. Tome VI: Section IX (“Critique textuelle et édition de textes"); 1998. p. $76-85$. 
Lopes GV, Ferreira MP et al. Cantigas Medievais Galego Portuguesas [base de dados online]. Lisboa: Instituto de Estudos Medievais, FCSH/NOVA; 2011.

Machado FAVL. Diálogos de São Gregório: Edição e estudo de um manuscrito medieval português. Salvador: EDUFBA; 2008.

Machado FAVL. Um flos sanctorum trecentista em português. Brasília: Editora Universidade de Brasília; 2009.

Machado FAVL. Lexicografia Histórica e Questões de Método. In: Lobo T, et al, organizadoras. Rosae: Linguística histórica, história das línguas e outras histórias. Salvador: EDUFBA; 2012. p. 381 390.

Machado FAVL. Dicionário etimológico do português arcaico. 1. ed. Salvador: Edufba; 2013.

Machado EP, Machado JP. Cancioneiro da Biblioteca Nacional, antigo Colocci-Brancuti, Lisboa; 1949-1964.

Maia CA. História do galego-português: estado linguístico da Galiza e do Noroeste de Portugal desde o século XIII até ao século XVI (com referência à situação do galego moderno). Coimbra: INIC; 1986.

Maia CA. Linguística Histórica e Filologia. In: Lobo T, et al, organizadoras. Rosae: Linguística histórica, história das línguas e outras histórias. Salvador: EDUFBA; 2012. p. 533-542.

Mattos e Silva RV. Caminhos da Linguística Histórica: ouvir o inaudível. São Paulo: Parábola; 2008.

Mattos e Silva RV. O português arcaico: fonologia, morfologia e sintaxe. São Paulo: Contexto; 2006.

Nunes B. Abreviaturas Paleográficas Portuguesas. Lisboa: Faculdade de Letras; 1981.

Oliveira AR. O trovador galego-português e o seu mundo. Lisboa: Editorial Notícias; 2001.

Oliveira AR. Trobadores e Xograres. Contexto histórico, Vigo, Edicións Xerais de Galicia; 1995.

Sampaio LRT. Cantigas satíricas do Cancioneiro da Biblioteca Nacional: Edição diplomática e estudo dos verbos em perspectiva lexicográfica [tese]. Salvador: UFBA; 2018.

Sampaio LRT. Edições e estudo do Livro dos Usos da Ordem de Cister, de 1415. São Paulo: NEHiLP/FFLCH/USP; 2014.

Scholberg KR. Sátira y invectiva en la España medieval. Madrid: Gredos; 1975.

Souza RB. Dos cancioneiros miscelâneos aos Liederbucher: problemas de edição da lírica profana galego-portuguesa. In: Tania Lobo et al. (Org.). ROSAE: linguística histórica e outras histórias. $1^{\circ} \mathrm{ed}$. Salvador: EDUFBA; 2012. p. 567-577.

Silva Neto S. História da língua portuguesa. Rio de Janeiro: Livros de Portugal; 1956.

Stegagno Picchio L. Os alhos verdes (Uma cantiga de escarnho de Johan de Gaya). In: A lição do texto. Filologia e Literatura. Lisboa: Edições 70; 1979.

Stegagno Picchio L. Martin Moya. Le Poesie. Roma: Ed. Dell'Ateneo; 1968.

Tavani G. Introdução à poesia medieval galego-portuguesa. Lisboa: Editorial Caminho; 2002.

Tavani G. A poesía de Airas Nunez. Vigo: Editorial Galaxia; 1992. 
Tavani G. Ainda sobre a tradição manuscrita. In: Ensaios Portugueses (retomado de Medioevo romanzo, VI, 1979). Lisboa: Imprensa Nacional-Casa da Moeda; 1988. p. 171-174.

Tavani G. Arte de Trovar do Cancioneiro da Biblioteca Nacional de Lisboa. Introdução, edição crítica e fac-simile. Lisboa: Edições Colibri; 1999.

Telles CM. Mudanças linguísticas e crítica textual. In: Almeida et al, organizadores. Estudos filológicos: linguística românica e crítica textual. v. 1.1 ed. Salvador: EDUFBA; 2016. p. 21-52.

Vasconcelos CM. Glosas Marginais ao Cancioneiro Medieval Português (trad. do texto de 1905). Coimbra: Acta Universitatis Conimbrigensis; 2004.

Vasconcelos CM. Cancioneiro da Ajuda, vol. I. Lisboa: Imprensa Nacional - Casa da Moeda (reimpressão da edição de Halle, 1904); 1990.

Vasconcelos CM. Cancioneiro da Ajuda, vol. II. Lisboa: Imprensa nacional - Casa da Moeda (reimpressão da edição de Halle, 1904); 1990.

Vieira YF. Pai Soarez de Taveirós e Peire Raimón de Tolosa. In: Atas del VIII Congresso Internacional de la Asociacion Hispánica de Literatura Medieval, vol. 1, Santander; 2001. p. 751-761. 